\title{
Episodic Cluster Headache in a Community: Clinical Features and Treatment
}

\author{
C.M. Riess, W.J. Becker and M. Robertson
}

\begin{abstract}
Objective: To study the clinical features and treatment given to episodic cluster headache patients in the Calgary region. Patients: Fifty-one (51) patients who responded to a media campaign, had previously been diagnosed by their family physicians, and who met International Headache Society (IHS) criteria for episodic cluster headache, formed the population for this study. Methods: The media campaign consisted of newspaper advertisements and radio publicity including physician interviews and talk shows. Patients were required to complete a 200 -item questionnaire detailing clinical features and treatment of their cluster headache syndrome. Each patient was also interviewed by our research nurse for clarification and proper completion of questionnaire. Results: Fifty-one percent (51\%) of our patients had short headache attacks lasting one hour or less. Almost one-half $(45 \%)$ had three or four attacks per 24 hour period. Eighty-six percent $(86 \%)$ had been referred to a neurologist. Sixty-nine percent $(69 \%)$ had never used oxygen, but of those who had, onehalf were still using it. Sumatriptan by injection had been tried by $26 \%$ of patients and of these, $93 \%$ considered it effective. Subcutaneous dihydroergotamine had been tried by $8 \%$. For prophylaxis, $41 \%$ had tried methysergide, $31 \%$ prednisone, and $4 \%$ verapamil. Many patients had been prescribed migraine prophylactic drugs which are ineffective for cluster headache, and some had also undergone dental procedures or nasal and sinus surgeries. Conclusions: Many cluster headache patients had not, to their knowledge, been prescribed or used the best symptomatic and prophylactic treatments for cluster headache. This should be addressed through educational programs and through making up-to-date information on the treatment of cluster headache readily available to physicians and patients.
\end{abstract}

RÉSUMÉ: Étude régionale sur la céphalée vasculaire de Horton: manifestations cliniques et traitement. Objectif: Le but de cette étude était d'étudier les manifestations cliniques et le traitement administré aux patients souffrant de céphalée vasculaire de Horton dans la région de Calgary. Patients: L'échantillon est constitué de cinquante et un (5I) patients qui ont répondu à une campagne médiatique. Ils avaient reçu ce diagnostic de leur médecin de famille et rencontraient les critères de l'IHS sur la céphalée vasculaire de Horton. Méthodes: La campagne médiatique comprenait des annonces dans les journaux et de la publicité à la radio incluant des entrevues avec des médecins et des émissions d'entrevues-variétés. Les patients devaient compléter un questionnaire de 200 items détaillant les manifestations cliniques et le traitement de leur céphalée. Chaque patient avait une entrevue avec notre infirmière de recherche pour clarifier et compléter adéquatement le questionnaire. Résultats: Cinquante et un pourcent ( $51 \%)$ de nos patients avaient des crises de céphalée de courte durée, soit de une heure ou moins. Presque la moitié (45\%) avaient trois ou quatre crises par 24 heures. Quatre-vingt-six pourcent (86\%) avaient été référés à un neurologue. Soixante-neuf pourcent (69\%) n'avaient jamais utilisé d'oxygène, mais parmi ceux qui en avaient utilisé, la moitié en utilisait encore. Vingtsix pourcent $(26 \%)$ des patients avaient essayé le sumatriptan en injection et parmi ceux-ci, $93 \%$ considéraient ce traitement efficace. Huit pourcent ( $8 \%$ ) avaient essayé la dihydroergotamine sous-cutanée. En prophylaxie, $41 \%$ avaient essayé le méthysergide, $31 \%$ la prednisone et $4 \%$ le vérapamil. Plusieurs patients avaient reçu une prescription de médicaments utilisés en prophylaxie de la migraine qui sont inefficaces pour les céphalées vasculaires de Horton et certains avaient subi des chirurgies des dents, du nez et des sinus. Conclusions: Plusieurs patients qui souffrent de céphalé vasculaire de Horton n'avaient jamais reçu à leur connaissance de prescription ou utilisé les meilleurs traitements symptomatiques ou prophylactiques pour ce genre de céphalée. Cette situation devrait être rectifiée par des programmes éducatifs et en informant les médecins et les patients du traitement de la céphalée vasculaire de Horton.

Can. J. Neurol. Sci. 1998; 25: 141-145

Cluster headache is an uncommon but well-defined clinical syndrome. Nevertheless, because it is relatively uncommon, it is difficult for the generalist to become very familiar with its diagnosis and treatment.

The clinical features of cluster headache are quite distinctive. According to the criteria of the International Headache Society (IHS),' the pain must be unilateral, occur in the temporal, orbital or supraorbital regions, and last (untreated) 15-180 minutes. The headache must be accompanied by at least one of the following signs, occurring ipsilaterally: lacrimation, conjunctival injection, rhinorrhea, forehead and facial sweating, nasal congestion, ptosis, miosis, and/or eyelid edema. Attack frequency must be between one every other day, to eight per day. Episodic cluster headache periods can last from seven days to one year, with remission periods of at least fourteen days; however, a typical cluster period will last between two weeks to three months.' Although a number of effective treatments are available to cluster headache sufferers, many patients surveyed by us seemed not to have tried many of these treatments. We undertook to study the clinical features and the treatments tried by a sample of episodic cluster headache patients in the Calgary region.

From the Department of Clinical Neurosciences, University of Calgary, Calgary, Canada. RECEIVED JUNE 2, 1997. ACCEPTED IN FINAL FORM OCTOBER 3, 1997.

Reprint requests to: W.J. Becker, Foothills Hospital, 1403 - 29th Street N.W., Calgary, Alberta, Canada T2N 2T9 


\section{METHODS}

Sixty-one patients who had previously been diagnosed by their physicians as suffering from cluster headaches and who responded with a telephone message to newspaper advertisements and a radio publicity campaign were telephoned by our study nurse. If patients appeared to meet IHS diagnostic criteria for cluster headache, they were asked to come into the Headache Clinic to complete a 200 item questionnaire. This questionnaire consisted of four parts: (1) diagnostic criteria, which ensured that patients met the criteria for episodic cluster headaches; (2) clinical features, which explored aspects of the patient's history and details of the headaches themselves; (3) health care utilization, which examined how many physician visits, hospital visits and diagnostic tests the patient had undergone; and (4) therapies, which included the types of symptomatic, prophylactic, and other therapies the patient had tried. For most questions, the patient had to choose one of a number of options for an answer. For example, when asked if they had ever used methysergide (Sansert) for prevention of cluster headache attacks, answer choices were "yes", "no" and "don't know". Most questions had a "don't know" option, so if patients were not sure if they had tried a particular medication, they could indicate that to us. After the questionnaire was completed, each patient was interviewed by our Headache Clinic Research Nurse for clarification and to ensure proper completion of each question. Fifty-one patients met the diagnostic criteria of the IHS for episodic cluster headache. The remainder either did not meet diagnostic criteria for cluster headache ( 9 patients) or had chronic cluster headache ( 1 patient). The questionnaire results of these 51 patients were analyzed further and form the basis for this report.

\section{RESULTS}

Demographics Of our 51 patients, $82 \%$ were male and $18 \%$ were female. Patient age range was $25-75$ years, with an average age of 45 years.

Duration of Cluster Headache Syndrome Fifty of the 51 patients had had cluster headache for over four years, and 41 patients had had cluster headache for over ten years.

Headache Attack Duration Usual duration was 15 minutes to 1 hour, $51 \%$ of patients; $1-3$ hours, $49 \%$.

Headache Frequency During a cluster, the usual number of attacks experienced in a 24 hour period was: $1-2,40 \%$ of patients; $3-4,44 \% ; 5-7,12 \%$. Four percent $(4 \%)$ of patients had one attack only every other day.

Cluster Duration This was as follows: $<4$ weeks, $26 \%$ of patients; 4-8 weeks, $50 \%$; $>8$ weeks, $24 \%$.

Remission Period Duration This was as follows: <1 year, $49 \%$ of patients; $1-2$ years, $33 \%$; $>2$ years, $18 \%$.

Accompanying Symptoms During Headache Attack These included: occasional nausea, $49 \%$ of patients; frequent nausea, $12 \%$, occasional vomiting, $24 \%$; frequent vomiting, $4 \%$.

Timing of Headache Attacks Attacks occurred during both day and night in $90 \%$, only during sleep in $6 \%$, and only during wakefulness in $4 \%$.

Trigger Factors Sixty-six percent $(66 \%)$ indicated that alcohol could trigger a headache during a cluster period. Six percent (6\%) did not drink. Eight percent $(8 \%)$ were uncertain, and $20 \%$ denied precipitation of headaches by alcohol. Fifty-seven percent $(57 \%)$ of our patients felt that other factors could precipitate their headaches, with the two triggers most commonly mentioned being bright lights (or glare), and stress.

Smoking Sixty-nine percent $(69 \%)$ were smokers when their headaches started (at least one-half package per day or more). One-third of patients were still smoking.

Shiftwork Seventy-one percent $(71 \%)$ had never done shift work. Only $14 \%$ were doing shift work during the year before their headaches started.

Sleep Disturbance Eighty percent (80\%) indicated that they had no major sleep disturbance in the year before their headaches started.

Depression History of depression in our patients was as follows: never treated for depression, $84 \%$; treated by family doctor only, $8 \%$; treated as out-patient by psychiatrist, $6 \%$; hospitalized for depression, $2 \%$; diagnosed with bi-polar disorder, $0 \%$.

Impact on Work and Personal Life Patients perceived the impact of cluster headache on these as follows: no major impact on work, $90 \%$; no major impact on personal relationships, $96 \%$; cause of job loss, $0 \%$; cause of marital separation, $2 \%$.

Coping Behaviours These varied from patient to patient and included pacing, banging the head and fists, sitting quietly, meditation and self-injury.

Family History This was as follows: father with cluster headache, $12 \%$ of patients; mother, $6 \%$; brother or sister, $6 \%$; total with at least 1 first degree relative affected, $22 \%$.

\section{Health Care Resource Utilization}

Family Physicians Number of family physicians seen for cluster headache: at least $1,100 \%$ of patients; at least $2,73 \%$; at least $5,20 \%$.

Neurologists Number of neurologists seen for cluster headache: at least $1,86 \%$ of patients; at least $2,20 \%$; at least 3 or more, $10 \%$.

Other Specialties Other medical specialists consulted for cluster headache included: dentists, $22 \%$ of patients; eye specialists, 14\%; ENT specialists, 10\%.

Other Health Professionals Other health professionals consulted for cluster headache included: chiropractors, $24 \%$ of patients; and acupuncturists, $12 \%$

Office Visits to Physicians for Headache Patients indicated they had made the following number of office visits for cluster headache: between 10 and $30,46 \%$; over $30,30 \%$.

Hospital Emergency Rooms Hospital Emergency Room use had been as follows: never used, $59 \%$ of patients; 3 visits or less, $24 \%$; more than 3 visits, $17 \%$.

Hospital Admissions Most patients (75\%) had not been admitted to hospital for their headaches. Those who had been admitted had spent anywhere from one to nine days in hospital.

Investigations Fifty percent (50\%) of patients had had at least one brain CT scan (4\% had had three), $8 \%$ had had an MRI scan and $6 \%$ had had a cerebral angiogram. Twenty-six percent $(26 \%)$ had had sinus $\mathrm{x}$-rays, $12 \%$ skull $\mathrm{x}$-rays and $10 \%$ neck $\mathrm{x}$ rays. Sixty-one percent $(61 \%)$ had had at least one EEG $(10 \%$ had had three EEGs or more).

\section{Treatment}

Oxygen Sixty-nine percent (69\%) had never used oxygen. Of those who had used it, most (11/16 patients) found it worthwhile. 
About one-half of those who had used oxygen found it generally successful. Of those who had ever used oxygen, $50 \%$ were still using it. Reasons given for stopping oxygen were that it was not effective enough (most common reason), too expensive or too inconvenient.

\section{Symptomatic Medications}

1) Virtually all patients had tried analgesics, but only $6 \%$ considered them an effective treatment (Figure). 2) Oral ergotamine had been tried by $57 \%$, but was considered an effective treatment by only a small minority ( $10 \%$ of those who had used it). None had tried ergotamine suppositories. 3) Dihydroergotamine was tried by only $8 \%$. 4) Oral sumatriptan was tried by $39 \%$. Of those, $9 / 20$ ( $45 \%$ of those who had used it) felt it had been an effective treatment. 5) Injectable sumatriptan was tried by only $26 \%$. Of these, $12 / 13$ ( $92 \%$ of those who had tried it) considered it to have been an effective treatment. No serious side effects were noted. Nine out of thirteen patients (9/13) indicated that they had had no side effects. Four out of thirteen (4/13) indicated significant but not serious side effects, such as body heaviness, tingling, dizziness, injection site pain, upset stomach, shortness of breath and heart palpitations. 6) Patients had tried many other therapies including deep breathing, magnetic belts, Indocid, biofeedback, meditation, reflexology, massage, herbs, vitamins and benzodiazepines. None were considered an effective treatment by anybody.

When asked which medication had worked best for symptomatic treatment of cluster headache, only sumatriptan, dihydroergotamine subcutaneously, and oxygen had more than single, positive responses from the 51 patients.

\section{Prophylactic Drug Therapy}

1) Forty-one percent $(41 \%)$ had been prescribed methysergide, with $5 / 21$ patients $(24 \%)$ considering it clearly effective and satisfactory. 2) Prednisone had been prescribed for $31 \%$, with 4/16 patients considering it clearly effective and satisfactory (25\% of users). 3) Lithium had been prescribed for $14 \%$, and was considered clearly effective and satisfactory by $1 / 7$ patients ( $14 \%$ of users). 4) Four percent (4\%) of patients had tried verapamil. 5) Propranolol had been prescribed for $33 \%$ of patients, with none considering it effective. 6) Pizotyline had been prescribed for $18 \%$, with none finding it effective. 7) Eight percent (8\%) had tried flunarizine with none considering it effective.

\section{Other Therapies for Cluster Headache}

1) Twenty-five percent $(25 \%)$ of patients had undergone dental treatment in an attempt to relieve their headaches. These included tooth extractions in $16 \%$ of patients. Individual patients had had root canals done, splints made and fillings replaced. None of the dental treatment was considered helpful. 2) Only five patients indicated that they had had non-dental surgery (two sinus surgery, and three nasal surgery) for treatment of cluster headache. Only one felt the surgery had been helpful.

\section{Discussion}

Clinical Features Cluster headaches should not be difficult to distinguish from migraine headaches, as migraine headaches are less frequent, longer lasting, and associated with much more nausea and vomiting. In one-half of our patients cluster headache attacks lasted one hour or less, and one-half had three or more headache attacks per day.

Alcohol during a cluster could trigger headache attacks in $66 \%$ of our patients. Levi et al. reported that alcohol could elicit an attack in $79 \%$ of their patients. ${ }^{2}$

Cluster headache attacks are very severe, so it is remarkable that almost all of our patients reported no major impact on their jobs, or personal relationships. Other authors have also noted that patients experiencing even $4-5$ attacks per day will endure the pain without missing work. ${ }^{3.4}$ Patients may find it easier to cope with cluster headache attacks, as opposed to migraine headache because the cluster headache attacks are much shorter and there are usually long periods of remission.

During cluster attacks various coping behaviours similar to those observed by us have been described by several authors. ${ }^{4-7}$ In our series, these actions could vary depending on which stage of the attack the patient was experiencing. For example, as his headache intensity increased, one patient would first pace, then exercise, then verbally release, and then bang his head and fists. Just after the intensity peaked, he would lie down quietly and try to relax.

Etiology While some authors have stated that cluster headache is not inherited, ${ }^{8-10}$ others have noted that a significant number of patients give a positive family history, suggesting a genetic component. ${ }^{11-15}$ In our patients, $22 \%$ reported a first degree relative with cluster headache. This figure probably overestimates the true familial occurrence of cluster headache, as we did not personally confirm the diagnosis in relatives, and some cluster headache sufferers will mistake migraine in relatives for cluster. ${ }^{14}$ Nevertheless, Russell et al. ${ }^{14}$ did find that first degree relatives of cluster headache patients had a fourteen-fold risk of cluster headache as compared to the general population. Kudrow and Kudrow found that $12 \%$ of cluster women and $10 \%$ of cluster men had at least one first degree relative with cluster headache. ${ }^{15}$

Cluster headaches are often considered to be a disturbance of circadian rhythms. Disorganized sleep however was not common in our patients during the year prior to cluster headache onset. Of interest, very few of our patients (only 16\%) listed depression as a possible co-morbidity. Several authors have reported a high incidence of smoking (ranging from $69 \%$ to $81 \%$ ) in cluster headache patients. $2.4,16,17$ Smoking was prevalent in our patients, with $69 \%$ smoking one-half pack per day or more when their headaches started. An elevated prevalence of peptic ulcer in cluster patients has also been suggested. . $^{38.10 .17}$ Only $10 \%$ of our patients reported any history of peptic ulcer. This incidence is lower than the studies cited by Kudrow ${ }^{17}$ and the $20 \%$ prevalence suggested by Mathew, ${ }^{3}$ and not different from the lifetime prevalence in the general population. ${ }^{18}$

Health Care Resource Utilization Neurologists were the specialists to whom these patients were referred most frequently, with $86 \%$ having seen a neurologist. Referrals to other medical specialists were much less frequent.

Hospital use was significant. Forty-one percent $(41 \%)$ had used hospital emergency rooms and $25 \%$ had been hospitalized for their headaches.

Although the cluster headache syndrome clinically is usually very distinctive, diagnostic investigations were frequently done. An investigation which might be considered quite worthless in this clinical setting, an EEG, was one of the most commonly done investigations. This may be in part because many of our 


\section{SYMPTOMATIC TREATMENTS}

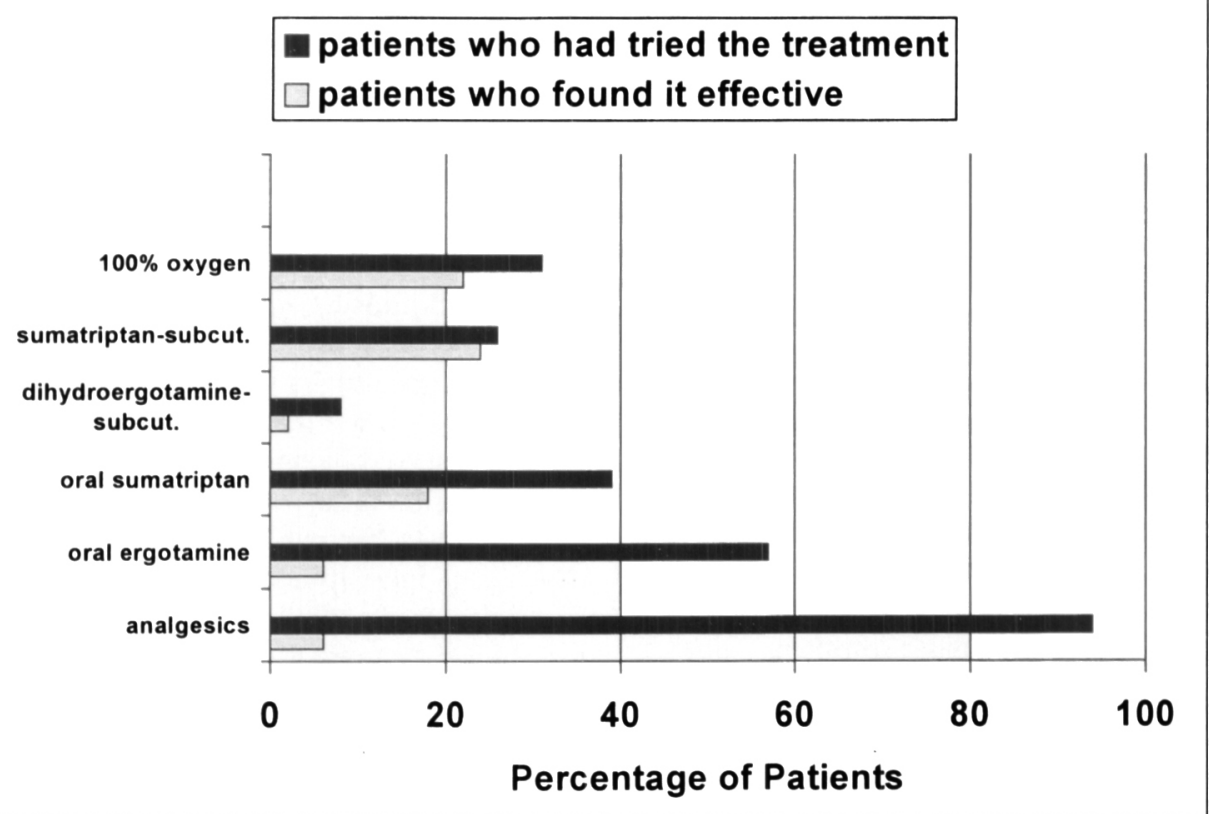

Figure: The percentage of patients $(n=51)$ who stated they had used each of the various acute therapies for cluster headache is shown by the black bars. The light bars show how many patients felt a treatment had been effective for them (again shown as a percent of the total patient population, $n=5 I$ ).

patients had had cluster headache for many years and until approximately ten years ago, family physicians in Calgary had much easier access to EEG than to neuro-imaging procedures.

Treatment Cluster headache is best treated by the initiation of both symptomatic and prophylactic treatment at cluster onset. With this approach, the symptomatic therapy, may be needed for only a relatively brief time period, until the prophylactic medication stops the cluster. The prophylactic drug is then usually continued for at least the expected duration of the cluster as based on the patient's past experience. Prednisone is an exception. This drug is usually given in a 2-3 week course, although if relapse of cluster headache occurs as the dose is tapered, a somewhat more prolonged course can be tried.

Symptomatic Therapy Because cluster headaches are intense but short, oral medications are generally not satisfactory, although widely used. Oral analgesics were found effective by only $6 \%$ of patients who had tried them, and oral ergotamines by only $10 \%$ of patients who had tried them. Surprisingly, oral sumatriptan was considered an effective treatment by $45 \%$ of the twenty patients who had tried it.

The three most effective available symptomatic treatments for individual cluster headache attacks are inhalation of $100 \%$ oxygen, sumatriptan by self-injection and dihydroergotamine (which may also be given subcutaneously by self-injection). ${ }^{19-26}$ Surprisingly few patients had ever tried these treatments. Sixty-nine percent $(69 \%)$ had never used oxygen (Figure). It is noteworthy that of those who had ever tried it, one-half were still using it.

Sumatriptan by injection had been tried by only $26 \%$ of patients. Of these, 93\% considered it effective (Figure). Dihydroergotamine had been tried by only $8 \%$.

Prophylactic Therapy For patients with episodic cluster headache, the three most effective prophylactic drugs for termi- nating a cluster are probably methysergide, prednisone (a short course of 14-21 days), and verapamil.6.10.17.27-29 Lithium might be a fourth choice, but is more difficult to use and is prescribed more for chronic cluster headache. Ergotamine in low doses is also used in a prophylactic fashion for a period of weeks by some, especially in the form of a regular dose at bedtime to prevent nocturnal attacks. Of our patients, only $41 \%$ had tried methysergide, $31 \%$ prednisone and $4 \%$ verapamil.

Many patients were prescribed prophylactic drugs which are effective in migraine, but much less effective in cluster headache (33\% had been given propranolol, and $18 \%$ pizotyline). No patient reported an effective result from these two migraine prophylactics.

Other Treatments Many patients had undergone dental and surgical procedures in an effort to resolve their cluster headaches.

Other investigations have also found that cluster headache sufferers often seek dental treatment. One study ${ }^{30}$ reported that cluster patients will often have midfacial pains and will therefore see a dentist. In this study, $42 \%$ of cluster patients received apparently inappropriate dental treatment. ${ }^{30}$ Education regarding cluster directed at dentists is needed.

Study Limitations and Conclusions The reasons why so many patients were apparently not prescribed the most effective symptomatic and prophylactic treatments for cluster headache are not clear. Many of our patients had had cluster headache for a long time, and may not have sought active therapy in the last several years. This could influence whether newer drugs like sumatriptan had been tried. The cost of some drugs may also have been a factor. Also, our study involved a questionnaire and depended upon patient recall. We cannot be sure how representative our sample of 51 patients was of the general cluster headache population. If cluster headache has a prevalence of approximately 0.4 
cases $/ 1000$ population as is generally asserted, ${ }^{31,32}$ then our sample of 51 patients was drawn from a pool of approximately 280 cluster patients in Calgary (approximate population 700,000). It is possible that our sample was biased toward the more severe end of the cluster headache spectrum, as such patients might be more likely to respond to a publicity campaign.

Cluster headache is a classic headache syndrome which has a distinctive clinical presentation and should not be confused with migraine. According to our results, the most effective therapies available are often not being utilized by cluster headache patients. In many cases, drugs effective for migraine but less effective for cluster headache, are being prescribed instead. Educational programs are needed, both for physicians and patients, to ensure that cluster headache patients receive the most effective treatments available. It is important that neurologists, the specialty group these patients are referred to most frequently, take a leadership role in these programs.

\section{ACKNOWLEDGEMENT}

This study was made possible by a grant from Glaxo-Wellcome Inc. Glaxo Wellcome in no way participated in the acquisition of the data or in the writing of the article.

\section{REFERENCES}

1. Headache Classification Committee of the International Headache Society. Classification and diagnostic criteria for headache disorders, cranial neuralgias and facial pain. Cephalalgia 1988; 8 (Suppl 7): 35-38.

2. Levi R, Edman GV, Ekbom K, Waldenlind E. Episodic cluster headache II. High tobacco and alcohol consumption in males. Headache 1992, 32: 184-187.

3. Mathew, NT. Cluster headache. Neurology 1992; 42 (Suppl 2): 2231.

4. Mathew, NT. Advances in cluster headache. Neurol Clin 1990; 8(4): 867-890.

5. Blau, JN. Behaviour during a cluster headache. Lancet 1993; 342: 723-725.

6. Solomon SS, Lipton RB, Newman LC. Prophylactic therapy of cluster headaches. Clin Neuropharm 1991; 14(2): 116-130.

7. Kudrow L. Diagnosis and treatment of cluster headache. Med Clin North Am 1991; 75(3): 579-594.

8. Krabbe AA. Cluster headache: a review. Acta Neurol Scan 1986; 74: $1-9$.

9. Kumar KL, Cooney TG. Headaches. Med Clin North Am 1995; 79(2): $261-286$.

10. Gabai IJ, Spierings ELH. Diagnosis and management of cluster headaches. Nurse Pract 1990; 15(10): 32-36.

11. Spierings ELH, Vincent AJPE. Familial cluster headache: occurrence in three generations. Neurology 1992; 42: 1399-1400.
12. Russell MB, Andersson PG, Thomsen LL. Familial occurrence of cluster headache. J Neurol Neurosurg Psychiatry 1995; 58: 341343.

13. Sjaastad O, Shen J-M, Stovner LJ, Elsås T. Cluster headache in identical twins. Headache 1993; 33: 214-217.

14. Russell MB, Andersson PG, Iselius L. Cluster headache is an inherited disorder in some families. Headache 1996; 36: 608-612.

15. Kudrow L, Kudrow DB. Inheritance of cluster headache and its possible link to migraine. Headache 1994; 34: 400-407.

16. Swanson JW, Yanagihara T, Stang PE, et al. Incidence of cluster headaches: a population-based study in Olmstead County, Minnesota. Neurology 1994; 44: 433-437.

17. Kudrow L. Cluster Headache. Oxford University Press. New York, 1980.

18. McGuigan JE. Peptic ulcer and gastritis. In: Isselbacher, Braunwald, Wilson et al., eds. Harrison's Principles of Internal Medicine, Thirteenth Edition. New York, McGraw-Hill Inc., 1994.

19. Fogan L. Treatment of cluster headache: a double-blind comparison of oxygen vs. air inhalation. Arch Neurol 1985; 42: 362-363.

20. Sabato FD, Fusco BM, Pelaia P. Giacovazzo M. Hyperbaric oxygen therapy in cluster headache. Pain 1993; 52: 243-245.

21. Drummond PD, Anthony M. Extracranial vascular responses to sublingual nitroglycerin and oxygen inhalation in cluster headache patients. Headache 1985; 25: 70-74.

22. Silberstein SD, Schulman EA, McFadden Hopkins M. Repetitive intravenous DHE in the treatment of refractory headache. Headache 1990; 30: 334-339.

23. Mather PJ, Silberstein SD, Schulman EA, McFadden Hopkins M. The treatment of cluster headache with repetitive intravenous dihydroergotamine. Headache 1991; 31: 525-532.

24. The Sumatriptan Cluster Headache Study Group. Treatment of acute cluster headache with sumatriptan. N Engl J Med 1991; 325: $322-326$

25. Hardebo JE. Subcutaneous sumatriptan in cluster headache: a time study of the effect on pain and autonomic symptoms. Headache 1993; 33: 18-21.

26. Monstad EK, Prusinski A, Cole JA, Pilgrim AJ, Noronha D. Subcutaneous sumatriptan in the acute treatment of cluster headache: a dose comparison study. Acta Neurol Scand 1993; 88: 63-69.

27. Gabai IJ, Spierings ELH. Prophylactic treatment of cluster headache with verapamil. Headache 1989; 29: 167-168.

28. Sjaastad O. Cluster headache syndrome. W B Saunders Company Ltd. London, 1992.

29. Green MW. Cluster headaches. How to recognize and treat them. Post Grad Med 1983; 73(6): 67-71.

30. Bittar G, Graff-Radford SB. A retrospective study of patients with cluster headaches. Oral Surg Oral Med Oral Pathol 1992; 73: 519-525.

31. Heyck H. "Cluster" - Kopfschmertz (Bing-Horton Syndrom?). Forstschr Neurol Psychiatr 1976; 44: 37-50.

32. Nappi G, Manzoni GC. Guidelines of Headache. London: John Libbey Eurotext. 1993. 